\title{
Analysis on Factors Affecting Performance of Indexing Investment
}

\author{
Lijun Chen ${ }^{13^{*}} \quad{\text { Yanxi } \mathrm{Li}^{1} \quad \text { Chenchen Ding }}^{1} \quad$ Shaohong Sun ${ }^{2}$ \\ 1.School of Economics and Management, Dalian University of Technology, No. 2 Linggong Road, Dalian \\ 116024, China \\ 2.Dalian Commodity Exchange, No.129 Huizhan Road, Dalian 116023, China \\ 3.China futures Market Monitoring Center, No.5 Financial Street, Beijing 100033, China \\ * E-mail of the corresponding author: chenljdut@163.com
}

\begin{abstract}
This article analyzes the current status of indexing investment performance in China and the characteristics of fund managers and fund management companies. It also theoretically analyzes the influence of these factors on indexing investment performance in terms of fund governance structure, characteristics of fund managers and fund companies, stock selection ability and timing ability. Next, it uses multiple regression analysis from three dimensions mentioned above to verify the influencing factors on investment performance. The results show that in terms of passive investment, fund tracking error is significantly negatively correlated with institutional holdings and fund managers' stock selection ability, and significantly positively correlated with fund managers' timing ability. Female fund managers' tracking errors are smaller. Institutional investors play a positive role in promoting the performance of active investment. The fund manager's stock selection ability can effectively reduce the fund's sensitivity to target index fluctuations, and the fund manager's timing ability can significantly improve the performance of fund allocation. Funds allocated by female fund managers will be less sensitive to target index fluctuations.
\end{abstract}

Keywords: indexing investment, performance, fund management, fund managers

DOI: $10.7176 /$ RJFA/12-22-01

Publication date: November $30^{\text {th }} 2021$

\section{Analysis on the Current Status of Indexing Investment Performance in China}

1.1 Asset allocation method and investment performance

Securities asset allocation methods are generally divided into two categories: active investment and passive investment. There are two important products in indexing investment market of China, namely passive index funds and enhanced index funds. The former completely passively replicates the index, while the latter uses most of the assets for passive investment, but at the same time uses a small portion of assets for active investment.

Different tracking target indexes have different components and even asset classes, which will cause certain interference when comparing the investment performance of different asset allocation methods. Therefore, this paper selects the CSI 300 Index and the index funds with the CSI 300 Index as tracking targets to compare the investment performance of passive and enhanced index funds.

Judging from the overall change trend of the CSI 300 Index in 2019, it is showing a tortuous upward trend (as shown in Figure 1.1). Among them, the CSI 300 Index fluctuated greatly in the first quarter. It rose from 3000 points at the beginning of the year to more than 4000 points, an increase of more than $33.3 \%$. It can be seen that the Shanghai stock market was generally good at that time, and a significant decline appeared from the second quarter, after which, the Shanghai and Shenzhen Index showed a creeping upward trend and returned to a high of 4000 points at the end of the year. From the perspective of trading volume, the peak of trading volume was mainly concentrated in the first half of the year, especially during the period when the market rose sharply. At that time, the trading volume was close to 35,000 . It can also be seen that trading volume indirectly promoted the development of Shanghai and Shenzhen stock markets to a large extent. The overall transaction volume in the second half of the year tended to stabilize, basically hovering around 10,000. It can be seen from the annual moving average that the fluctuation range in the first half of the year was large, and the market tended to stabilize in the second half of the year.

The tracking error and daily rate of return of passive funds are less than enhanced funds. Figure 1 classifies the index funds according to the type, and plots the relationship between the tracking error and the rate of return of different funds according to the grouping of passive funds and enhanced funds. From the figure, we can clearly see that the tracking error of passive funds in general is significantly smaller than that of enhanced funds; correspondingly, the daily return rates of enhanced funds are mostly higher than passive funds. However, this conclusion is not absolute. In the lower part of the left picture, we can see that there are several passive funds with high tracking errors and enhanced funds with low daily rate of return. This may be related to the characteristics of the fund itself. From the perspective of the degree of dispersion, the concentration degree of passive funds is significantly higher than that of enhanced funds. This is due to the relatively small degree of differentiation of 
passive funds.

Most fund investments are concentrated in the manufacturing and financial industries, which have the characteristics of low tracking error and high daily rate of return. In Figure 2, we divide funds in terms of the investment ratios in different industries. On the whole, most investments made by funds are mainly concentrated in the manufacturing and financial industries. Some funds are concentrated on the upper left side of the right chart, which is characterized by low tracking error and high daily rate of return. And the fund on the upper right side of the picture, from the perspective of the distribution of investment industries, this fund is significantly different from others. Industries of its fund investments are more scattered, including manufacturing, finance, education, health and social work, business and leasing, among which the investment ratio in the financial industry is significantly smaller than others. Therefore, it is preliminarily judged that the high tracking error characteristic of this fund may be largely related to the investment composition of the fund, and investment in the financial industry is likely to be effective in reducing tracking error.

Passive funds perform better in terms of tracking errors, but enhanced funds have better performance in terms of their ability to adjust to market changes and the rate of return per unit risk. Figure 1.3 compares six performancerelated indicators of the passive fund and the enhanced fund in terms of tracking error, beta, Sharpe ratio, Treynor ratio, Jensen ratio and information ratio. First of all, from the point of view of tracking error, whether it is calculated by absolute value method or standard deviation method, the tracking error of passive funds is significantly smaller than that of enhanced funds. However, the tracking error obtained by using different methods is still different in different types of funds. Among them, the tracking error calculated according to the absolute value method is significantly smaller than the standard deviation method, and the gap between the upper and lower quartiles in the enhanced fund by using the standard deviation method is also significantly higher than the absolute value method. Because tracking error is a commonly used indicator to measure fund performance. We can preliminarily judge from the above figure that the performance of passive funds is better than enhanced funds.

Since the beta value is mainly used to quantify the volatility of individual investment instruments relative to the entire market, the higher the beta value of a security, the greater the potential risk and the higher the investment income, and vice versa. From the figure above, it can be seen that the difference in the beta value of passive funds is small and the value is large, while the difference in beta value of the enhanced fund is relatively large and the value is small, so it can be seen that passive funds bear higher potential risks.

Since the Sharpe ratio reflects the ability of fund managers to adjust to market changes, a higher value usually means that the fund has a better performance. From the figure above, we can see that for passive funds, the difference in Sharpe ratio is not obvious, while the Sharpe ratio of enhanced funds also shows differentiated characteristics due to the difference in investment strategies of different fund managers. In terms of the numerical distribution of the Sharpe ratio, passive funds are mainly concentrated between 0.1 and 0.12 ; while the Sharpe ratio of enhanced funds has a larger distribution span, mainly concentrated between 0.1 and 0.14 , which also reflects from the side that the ability of enhanced funds to adjust to market changes is stronger than passive funds.

Judging from the distribution of the Treynor, the value of enhanced funds is significantly higher than that of passive funds, which mainly reflects the relationship between income and market risk, and whether the market is in an up or down period, the higher the index Shows that the fund has performed better. Therefore, an analysis of the two types of funds in the direction of the Treynor can show that enhanced funds have a higher rate of return than passive funds under a certain level of risk. The use of the Jensen ratio mainly provides a more scientific way to measure the excess return rate of the fund. It can be seen from the above figure that the distribution of the Jensen ratio of passive funds is relatively small, mainly concentrated between 0 and $1.25 \times 10^{\wedge}(-4)$, while the distribution of the enhanced fund index is mainly concentrated between $1.25 \times 10^{\wedge}(-4)$ and $3.75 \times 10^{\wedge}(-4)$, enhanced funds are more likely to create excess returns for investors.

The information ratio mainly measures the risk-adjusted excess return of a certain investment portfolio better than a specific index. The larger the information ratio, the higher the excess return per unit of the fund manager's tracking error. Therefore, funds with a high information ratio usually have better performance. It can be seen from the figure above that the information ratio of enhanced funds in the overall distribution is slightly higher than that of passive funds, but the difference is not obvious.

Table 1 uses different indicators to compare the performance of two different types of funds, from the perspective of the respective evaluation indicators of different types of funds. The performance of enhanced funds is better than passive funds to a certain extent.

The fourth column is the comparison between enhanced and passive funds. From the difference of the tracking error (absolute value algorithm, standard deviation algorithm), the difference using the two algorithms is 0.0011 and 0.0017 , and significance level of both is $99 \%$, indicating that the difference in tracking errors between the two funds is obvious, and the passive funds must have better performance. The difference in beta between enhanced funds and passive funds is -0.0633 , and it is significant at the $95 \%$ level, indicating that passive funds bear higher potential risks than enhanced funds. The Sharpe Ratio and Treynor ratio are both positive in the comparison of enhanced funds and passive funds, and are significant at the $99 \%$ level, indicating that enhanced funds have greater 
ability to adjust to market changes and the rate of return per unit risk. good performance. However, the difference between the two types of funds in the Jensen ratio and the information ratio is not significant, and it is difficult to draw an exact conclusion based on this.

\subsection{Index fund categories and investment performance}

Figure 4 shows the core density map of the performance indicators of various index funds, which is used to compare the distribution of four different index funds (stock type, bond type, commodity type and QDII) under different performance indicators. The higher in the nuclear density map, which means the more concentrated the data, the more samples; otherwise, the more scattered. The distribution of the sample can be seen in the nuclear density map, and then we can make a rough judgment on different index funds. However, under certain indicators, the gap between various index funds is small. It is impossible to draw conclusions just by looking at the nuclear density map. Further performance analysis is necessary.

In terms of tracking error, stock funds $>$ commodity funds $>$ bond funds; bond funds have higher risk of adjusted excess returns. Table 2 lists the mean value of stock, bond and commodity investment performance indicators and the mean difference between the two groups. Whether it is the absolute value method or the standard deviation method, stock funds have the largest tracking error, followed by commodity funds, and bond funds have the smallest tracking error. In addition, we found that the beta value of bond funds is smaller than the other two types of funds, and its Sharpe ratio is larger than the other two types of funds, and the difference in the mean is significant at the $1 \%$ level. This shows that the correlation between the bond fund's yield and the tracking target index's yield is relatively small, but per unit risk exposure will produce more excess returns. Similar to this indicator is the Jensen ratio. The Jensen ratio of bond funds is significantly larger than the other two types of funds. The information ratio is used to measure the level of risk-adjusted excess return of a certain investment portfolio better than a specific index. We have also reached a similar conclusion that the risk-adjusted excess return of bond funds is higher.

Generally speaking, the average value of most performance indicators differs significantly among different types of index funds, but the difference of the Treynor ratio between between different types of index funds is not very significant. This may be because the Treynor ratio assumes that the fund can fully diversify the non-systematic risk of the investment portfolio, and the non-systematic risk is 0 . In actual investment, the fund cannot completely diversify the non-systematic risk. This way makes the evaluation effect of this indicator greatly reduced.

\subsection{The distribution characteristics of index fund managers and management companies}

The fund managers of index funds are mostly men. As shown in Figure 5, among the fund managers (1776 people) of all index funds, there are 403 women, accounting for $22.7 \%$; there are 1,373 men, accounting for $77.3 \%$. Among them, there are 1,025 male fund managers with the first signature of an index fund, accounting for $74.9 \%$, and 344 female fund managers, accounting for $25.1 \%$. Among the fund managers with second and third signature of an index fund, there are 348 males, accounting for $85.5 \%$, and 59 females, accounting for $14.5 \%$. It can be seen that men account for a larger proportion of fund managers.

Most fund managers of index funds have a master's degree. As shown in Figure 6, among the fund managers of all index funds (1776), 93 fund managers have a bachelor degree, accounting for 5.2\%; and 280 fund managers with a doctoral degree, accounting for 15.8\%; most fund managers have master degrees, and there are 1403 people, accounting for $79 \%$. Among the fund managers with the first signature of an index, 83 and 240 fund managers with bachelor's degree and doctoral degree, accounting for $6.1 \%$ and $17.5 \%$, respectively, and 1,046 fund managers with master's degree, accounting for $76.4 \%$. Among the fund managers with the second and third signature in an index fund, 10 and 40 managers have a bachelor's degree and a doctoral degree respectively, accounting for $2.5 \%$ and $9.8 \%$, respectively. There are 357 fund managers with a master's degree, accounting for $87.7 \%$.

\section{Analysis on factors affecting indexing investment performance}

2.1 Problems in fund governance

2.1.1 Principal-agent and separation of two rights

The main problem to be solved by fund governance is the agency problem under the separation of ownership and management. As an indirect financing method, the fund has a two-level contractual arrangement to reflect the entrust relationship, whether it is a corporate fund or a contractual fund. The first level is embodied in the fund holder (ultimate client) handing over assets to the fund management company to set a investment portfolio; the second level is embodied in the fund management company entrusting the fund assets to the company's manager (fund manager) to operate. The endogenous two-tier agency relationship of the fund produces information asymmetry among fund holders, fund management companies, and fund managers, which can lead to behaviors such as net worth manipulation, insider trading, and related party transactions, which make the fund reflect the interests of fund managers rather than fund holders in the actual operation process. The establishment and implementation of incentive and restraint mechanisms are important means to improve fund performance. Fund 
governance is to reduce agency costs and agency risks by establishing a set of reasonable governance structures and effective governance mechanisms to achieve the goal of checks and balances of power and scientific decisionmaking.

There are severe insider control problems in the fund industry of China, which are mainly manifested in: On the one hand, fund managers ignore the interests of fund investors for their own interests. The fund manager has the right to operate and control, and its goal is to maximize the net asset value of the fund in order to extract more management fees, but the net asset value of the fund is not equal to profits realized by the fund. On the other hand, large shareholders harm the interests of small shareholders. Because the fund's equity is dispersed and the degree of equity concentration is not high, the cost of a single fund holder's participation in fund governance is greater than the benefits he obtains, so his optimal strategy is to wait for people with higher fund shares to participate in fund governance. Under normal circumstances, when the "free rider" idea of small and medium fund share holders exists for a long time, large shareholders will use this control to implement related-party transactions and other behaviors.

The main reason for the problem of internal control of funds in our country is the excessive dispersion of fund holders. Most fund holders have a "free rider" mentality, so it is difficult to convene a fund holder meeting. The process and procedures for changing fund managers and custodians are more complicated. This makes it impossible for existing fund holders meeting to carry out the supervisory function of the fund manager and the independent selection function of the fund custodian. Therefore, China urgently needs to improve the governance system of funds to protect the interests of investors.

\subsubsection{Information asymmetry}

Compared with investors, fund managers have information advantages. Information asymmetry theory means that in market activities, various types of people participating in the market have different levels of understanding of relevant information, and participants who have relatively sufficient information are often in an active position, while those who lack information are in a relative passive position. The theory believes that the seller in the market knows more about the full range of information about the product than the buyer; the seller (the party with the larger amount of information) can make a profit in the market by passing information with certain value to the buyer (the party with the smaller amount of information); The buyer and seller with less information will try to obtain information from the other.As far as the securities investment market in China is concerned, the problem of information asymmetry is not only reflected in the amount of information, but more importantly, in the accuracy of the information obtained, so it has a certain particularity. Judging from the actual situation of fund companies in China, the information of funds is mainly disclosed in the form of quarterly financial statements, and the distribution of the main investment targets in the investment portfolio is only mentioned in the semi-annual and annual reports. Therefore, during the semi-annual report and annual report disclosure period, investors cannot obtain any information about the fund's investment structure. This allows fund managers to obtain certain information advantages.

\subsubsection{Incomplete contract}

Incomplete contract theory believes that due to the limited rationality of the market, the asymmetry of information, and the uncertainty of transactions, the cost of determining all special powers is too high. Therefore, it is impossible to draw up a complete contract. Incomplete contracts are inevitable and universal. Therefore, there is a struggle for residual control of assets. When the contract is incomplete, it is efficient to allocate residual control rights to the party whose investment decision is relatively important.

For China, all funds belong to the category of contractual funds. Fund holders and fund management companies sign contracts to entrust funds to fund management companies for investment management; at the same time, fund management companies sign contracts with fund managers on behalf of fund holders, and fund management companies sign contracts with fund custodians and other institutions. Fund companies are undoubtedly in the most critical position as fund management party.

In China, the fund management company is both the sponsor of the fund and the manager of the fund, and it is obliged to formulate various contract clauses related to fund investment. When there is a situation that is not stipulated in the contract, the fund company has almost all residual control rights, which can easily lead to selfinterested behavior when the fund company exercises the residual control rights, thereby damaging the interests of fund holders. At the same time, since the fund holders are mainly ordinary investors, the information asymmetry exacerbates this disadvantage, and they cannot judge whether the fund company has any behavior that harms the interests of investors when exercising residual control rights. This is the first that is the default of the fund manager. Although this kind of situation is bad, it is not common, so the harm is relatively low and controllable. There is another situation that is more common and the hidden harm is more serious. We usually call it the "inaction" situation of the fund manager. When the market changes drastically, it is often difficult for fund companies to respond in time, especially when conflicts of interest occur within the company, and the fund manager as the actual operator of the fund is the most direct exerciser of residual control rights, in order to protect its own interests from infringement, fund managers will often act aggressively or wait and see, which indirectly brings losses to investors. 


\subsection{The impact of fund governance structure on investment performance}

There is a significant positive correlation between the shareholding ratio of institutional investors and investment performance. Institutional investors have sufficient information resources and are more sensitive to market responses. Therefore, when institutional investors hold more shares of the fund, it will put some pressure on the fund management company to strengthen the effect of external supervision and improve fund performance. When more fund shares are held by institutional investors, it has the effect of external supervision, which can prompt fund managers to disclose fund information in a more timely and accurate manner, accelerate dispersion and reduction of non-systematic risks, and promote increasing the average excess rate of return caused by unit tracking errors, thereby improving investment performance. However, in China, fund holders' shares are too scattered and the degree of concentration is not high, which restricts the improvement of investment performance to a certain extent.

\subsection{The impact of fund managers and fund company characteristics on investment performance}

In the process of indexing investment, the fund manager is the direct manager of the fund, which determines the investment direction and investment timing of the fund, and the personal characteristics of the fund manager such as experience, education background, age, gender, etc. may affect the fund investment direction and timing of investment.

Female fund managers can significantly reduce the level of risk-taking, and a higher degree of education does not mean a higher return on investment, but means stronger risk control ability. Because men and women have different tolerances for risk, which has a certain impact on investment styles, many scholars have conducted research on the gender and performance of fund managers. The results show that men trade more frequently than women and are more confident excessively than women. Compared with men, women are more risk-averse and less self-confident, so the net income of the fund should be higher; fund managers with rich experience and doctorates have more advantages in risk control.

Fund companies play an important role in the investment process, and the different characteristics of fund companies have an impact on fund performance. The proportion of independent directors, the proportion of major shareholders' shareholding, and the proportion of financial shareholders will all have a positive impact on fund performance. The study found that in the board of directors of a fund management company, the greater the proportion of independent directors with professional knowledge and experience in the total number of board members, the higher the fund performance and the lower the net asset expense ratio. There is a certain relationship between the company's equity structure and fund performance: a certain degree of equity concentration can promote the improvement of fund performance; the proportion of major shareholders, the control of major shareholders, and the proportion of financial shareholders will all have a positive impact on fund performance. By establishing a multiple linear regression model, scholars have studied the relationship between the equity structure of management companies and fund performance in China's securities investment funds, and have come to the following conclusions. Firstly, major shareholders can promote fund performance. The largest shareholder's advantage in holding is more obvious, and this kind of promotion effect is better. Increasing the number of minority shareholders under the premise of high equity concentration can strengthen the supervision effect and improve the performance of the fund. Secondly, the fund performance of fund companies with a background of securities firm holding is better; foreign holdings do not have a significant impact on fund performance. Thirdly, the larger the scale, the better the performance of fund management companies, indicating that there is still a scale effect in China's fund management companies. The larger the scale of the company, the better resources, such as fund managers with higher capabilities, more timely and accurate information, etc., so there will be more funds with better performance.

\subsection{The impact of stock selection ability and timing ability on investment performance}

The capital invested by fund holders is a prerequisite for the growth of fund performance. What really enables the fund to achieve wealth growth is the professional knowledge possessed by the fund manager and the degree of application of this knowledge. The capital of fund holders has a strong dependence on human capital of fund managers. In the process of fund investment, the fund manager's stock selection ability and timing ability have an important impact on investment performance.

The timing ability of the fund manager means that the fund manager proactively increases the $\beta$ value of the investment portfolio before the market strengthens based on his own prediction of the future development trend of the capital market, so as to obtain more income from the market rise. When the market is predicted to weaken, the fund manger take the initiative to lower the $\beta$ value to avoid asset shrinkage caused by systemic risks, so that excess returns can be obtained under the two-way market trend. The stock selection ability of a fund manager means that the fund manager can identify those investment objects in the market that have been incorrectly valued relative to the industry or economic conditions, buy when the object is undervalued, and sell when the target is overvalued, so as to enable the asset portfolio to obtain excess returns that exceed the market. If the fund manager 
has the ability to select stocks and timing, the funds he manages will have higher investment efficiency. The empirical results show that open-end fund managers have certain timing and stock selection capabilities, but not significant; stock fund managers have relatively strong stock selection and timing capabilities in a bull market; in the case of multiple style classifications, most value and growth funds have timing ability.

\section{Analysis on factors affecting indexing investment performance}

\subsection{Data source}

Research data comes from Wind database (WIND) and Guotaian database (CSMAR). The sample covers 822 index funds from 2008 to 2019 . After deleting the samples with less than 100 trading days in one year and removing the missing values, a total of 2257 observations were obtained. Stata15 is used for data processing and regression analysis.

\subsection{Variables and descriptive statistics}

Indexing investment performance is the explained variable of the study. Among them, tracking error (absolute value method and standard deviation method) TE (abs) and TE (sd) are used to measure passive investment performance, and beta coefficient (beta) and Sharpe ratio(sharpe), Treynor ratio (treynor), Jensen ratio (jensen), information ratio (inf), characterize active investment performance. In addition, referring to the analysis in the second part of this article, the explanatory variables screen indicators from three levels mainly: fund governance structure, fund manager characteristics, and fund company attributes. The fund governance structure mainly includes institutional holding ratio (ins) and fund management company self-holding ratio (fund); fund manager characteristics mainly include manager gender (female), manager education (doc/bac), manager timing ability (mta), and manager stock selection ability (ssa); the attributes of fund companies mainly include the number of funds under the fund company (ln(numfund)) and the number of fund managers under the fund company $(\ln ($ numman)). In order to control the impact of other factors on indexing investment performance, referring to existing research, this part of the research also controls the international financial environment (iefei), domestic economic policies (depi), investor sentiment(conf), and fund size $(\ln ($ asset)), reweight unit net asset value (nav) and other related control variables. Specific variable definitions and descriptive statistics are shown in Table 3 and Table 4 (see Appendix).

\subsection{Fund governance structure and investment performance}

The regression results with passive investment performance as the explained variable show that the ins coefficient is -0.038 and is significant at the $1 \%$ level, indicating that the fund tracking error is significantly negatively correlated with the institutional holding ratio. As the institutional holding ratio increases, the tracking error of the fund will gradually decrease. But the tracking error of the fund has a significant positive correlation with the fund management company's self-holding ratio (fund), indicating that the self-holding behavior of the fund management company may cause the fund to deviate from the underlying index. Regarding the control variables, tracking error is significantly negatively correlated with fund size $(\ln ($ asset $))$, significantly positively correlated with investor sentiment (conf), and significantly negatively correlated with international macro financial environment (iefei).

The regression results with passive investment performance as the explained variable show that the regression coefficient of institutional holding ratio (ins) and beta is -0.051 , and it is significant at the $1 \%$ level, indicating that institutional holders can reduce the sensitivity of fund investment performance. Institutional holding ratio and sharpe ratio and inf both show a significantly positive correlation, indicating that compared with individual investors, institutional investors have advantages in professional skills, information channels, etc., which have a positive effect on the performance of active investment.

\subsection{Fund managers and investment performance}

The regression results using passive investment performance as the explained variable show that although the female coefficient is not significant, the coefficients are all negative. To a certain extent, when the fund manager is a female, the tracking error of passive investment is small, which is different from the consistent understanding that women are more cautious than men. In addition, the doc coefficients of the results are 0.024 and 0.036 respectively, and significant at the $1 \%$ and $5 \%$ levels, indicating that highly educated fund managers may not completely copy the underlying index components when conducting passive investment fund portfolios, but making use of their knowledge, adding more non-replicating components.

The regression result with active investment performance as the explained variable shows that the female coefficient is -0.014 and is significant at the $5 \%$ level, indicating that the funds managed by female fund managers are less sensitive to target index fluctuations than men. Although the Treynor ratio is not significant for female, it is negative, indicating that the performance of funds managed by female may be lower after considering only systematic risks. However, the sharpe ratio and the female coefficient are positive and the information ratio and 
the female coefficient are positive, indicating that after excluding non-systematic risks and risk adjustment, the performance of funds managed by female is better.

\subsection{Stock selection ability, timing ability and investment performance}

The regression result with passive investment performance as the explained variable shows that the mta coefficient is -0.144 and is significant at the $5 \%$ level, indicating that the fund manager's stock selection ability is significantly negatively correlated with tracking error. The stronger the stock selection ability, the degree of deviation from the tracking target is smaller. The ssa coefficient is 0.055 and is significant at the level of $10 \%$, indicating that the timing ability of the fund manager is significantly positively correlated with the tracking error. The stronger the timing ability is, the greater passive investment deviates from the tracking target.

The regression results with active investment performance as the explained variable show that the mta coefficient is -0.764 and is significant at the $1 \%$ level, indicating that the fund manager's stock selection ability can effectively reduce the fund's sensitivity to target index fluctuations. The beta and ssa show a significant positive correlation, indicating that the fund manager's timing ability not only cannot reduce the fund's sensitivity to target index fluctuations, but also increases the sensitivity to a certain extent. After considering only systematic risks, the stronger the fund manager's stock selection ability is, the worse the fund is allocated. When both systematic and non-systematic risks are considered, the stronger the fund manager's ability to select stocks is, the better the fund he allocates. This positive correlation can also be established by using the Jensen ratio. Regarding the timing ability of the fund, no matter what performance evaluation method exists, the coefficients of ssa are positive, and most of them are significant at the $1 \%$ level. It shows that the timing ability of fund managers can significantly improve the performance of fund allocation.

\section{Conclusion}

First, this article analyzes the current status of indexing investment performance in China and the characteristics of fund managers and fund management companies. Second, it also theoretically analyzes the influence of these factors on indexing investment performance in terms of fund governance structure, characteristics of fund managers and fund companies, stock selection ability and timing ability. Finally, it uses multiple regression analysis from three dimensions mentioned above to verify the influencing factors on investment performance. The results show that in terms of passive investment, fund tracking error is significantly negatively correlated with institutional holdings and fund managers' stock selection ability, and significantly positively correlated with fund managers' timing ability. Female fund managers' tracking errors are smaller. Institutional investors play a positive role in promoting the performance of active investment. The fund manager's stock selection ability can effectively reduce the fund's sensitivity to target index fluctuations, and the fund manager's timing ability can significantly improve the performance of fund allocation. , Funds allocated by female fund managers will be less sensitive to target index fluctuations.

\section{Appendix}

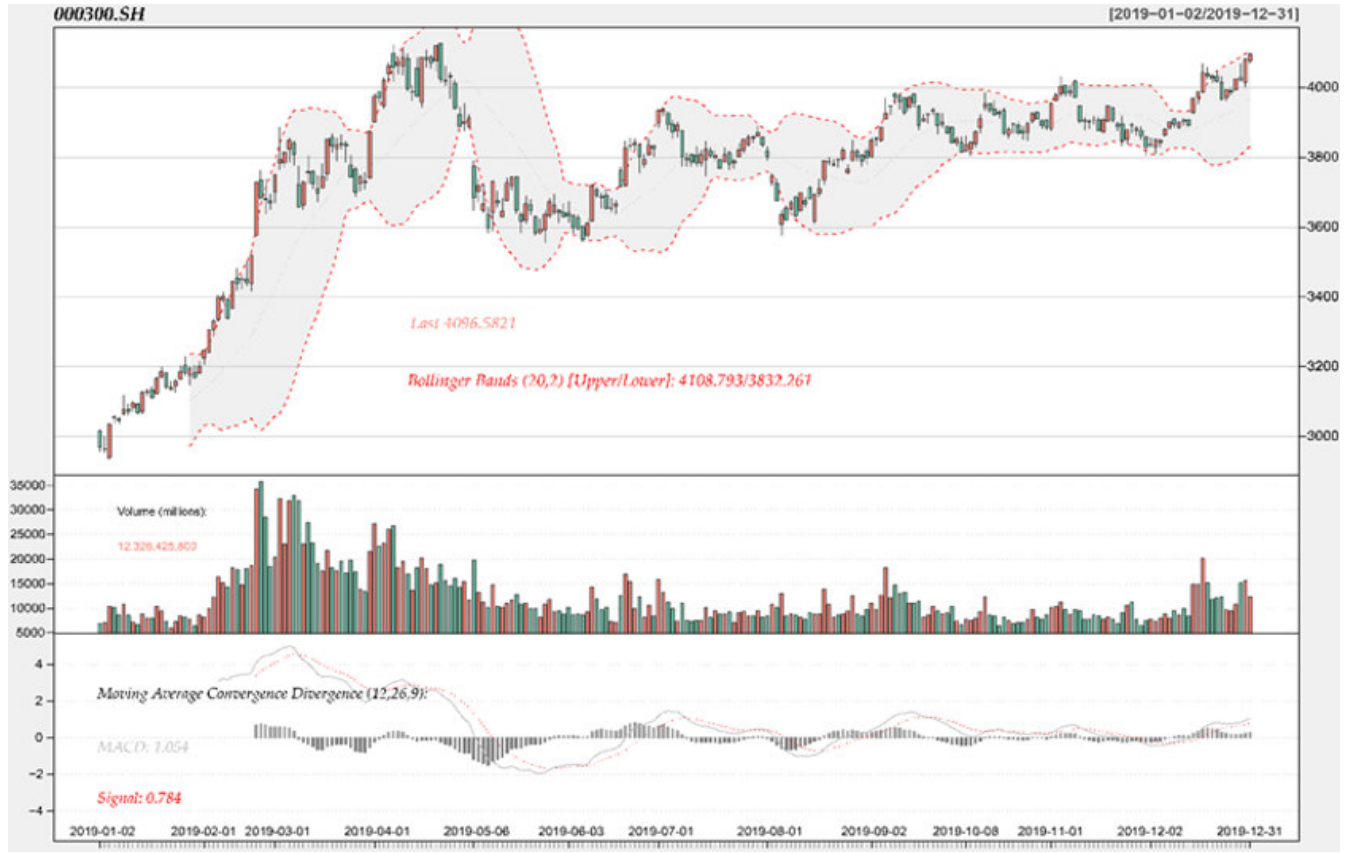

Figure 1. Market trends of the CSI 300 Index in 2019 

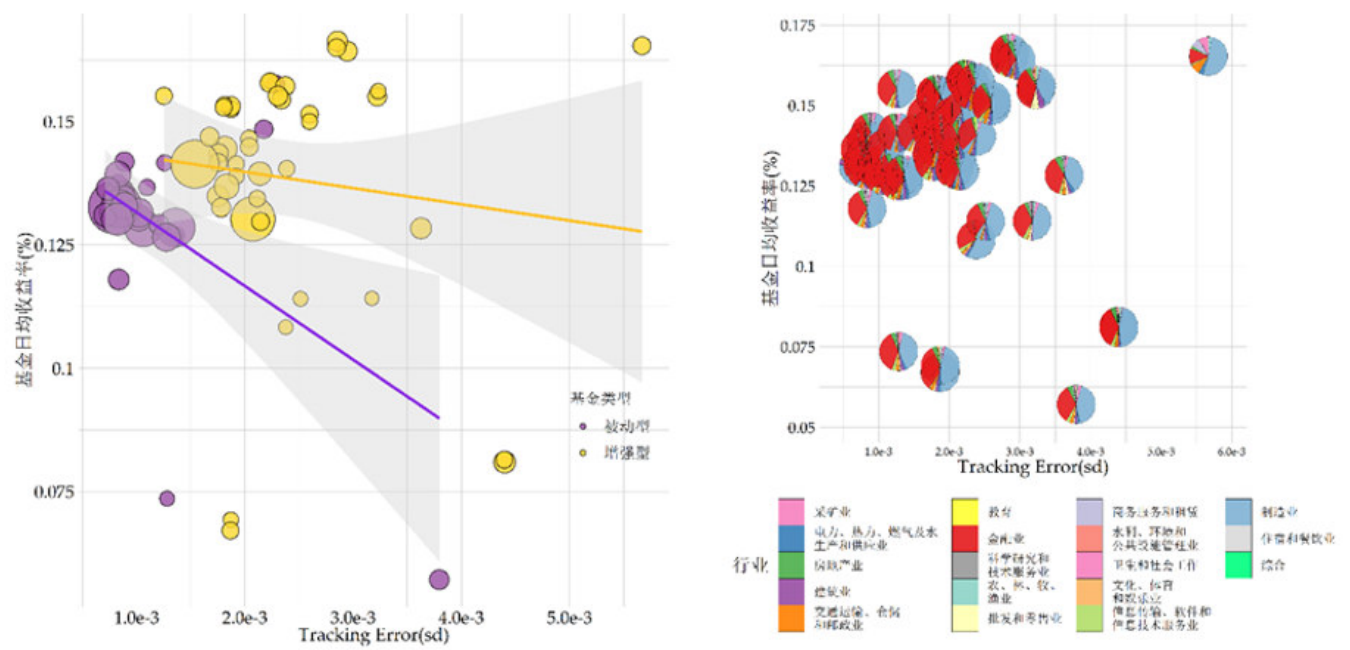

Figure 2. Tracking Error and Yield of CSI 300 Index Fund

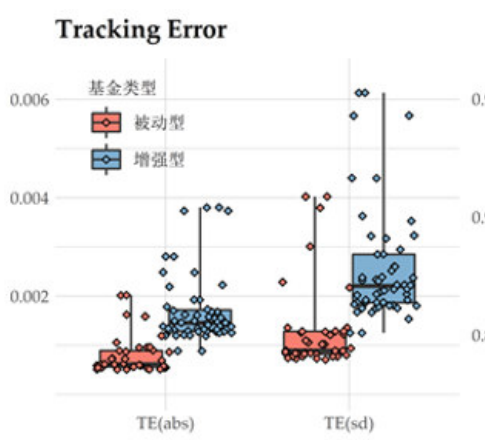

Beta

\section{Sharpe Ratio}

基金类型

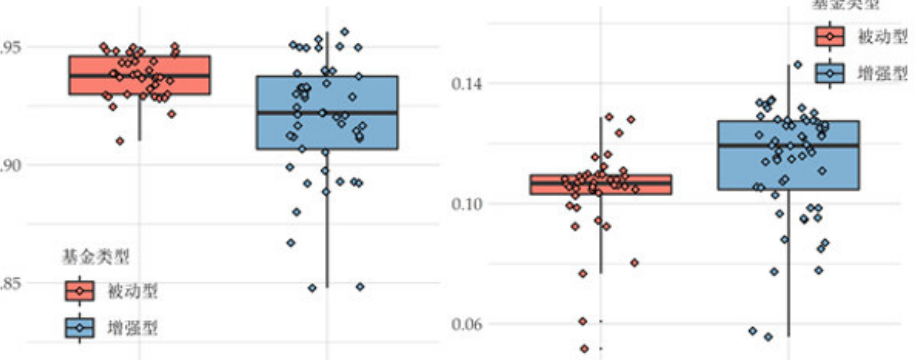

Treynor
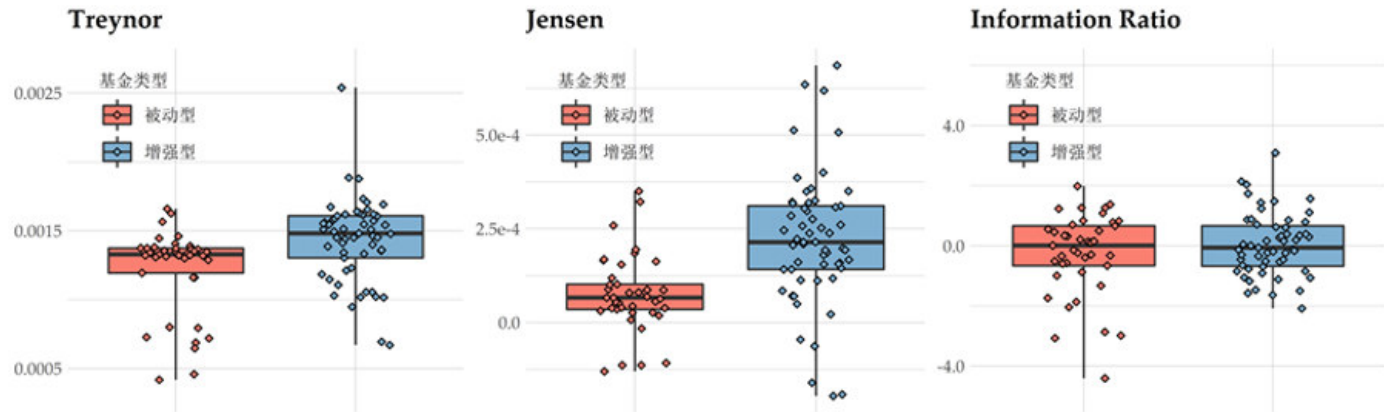

Information Ratio

Figure 3. Comparison of passive and enhanced index fund performance indicators 


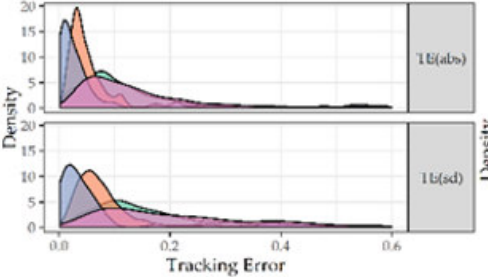

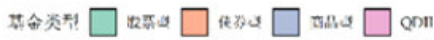

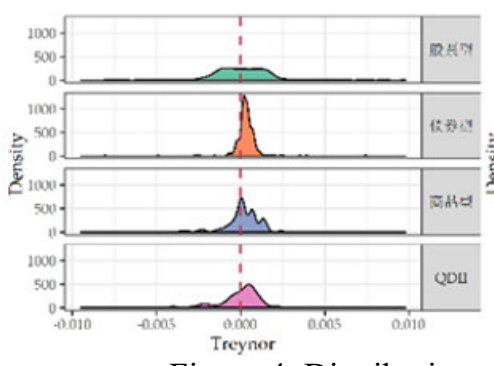

Figure 4. Distribution of
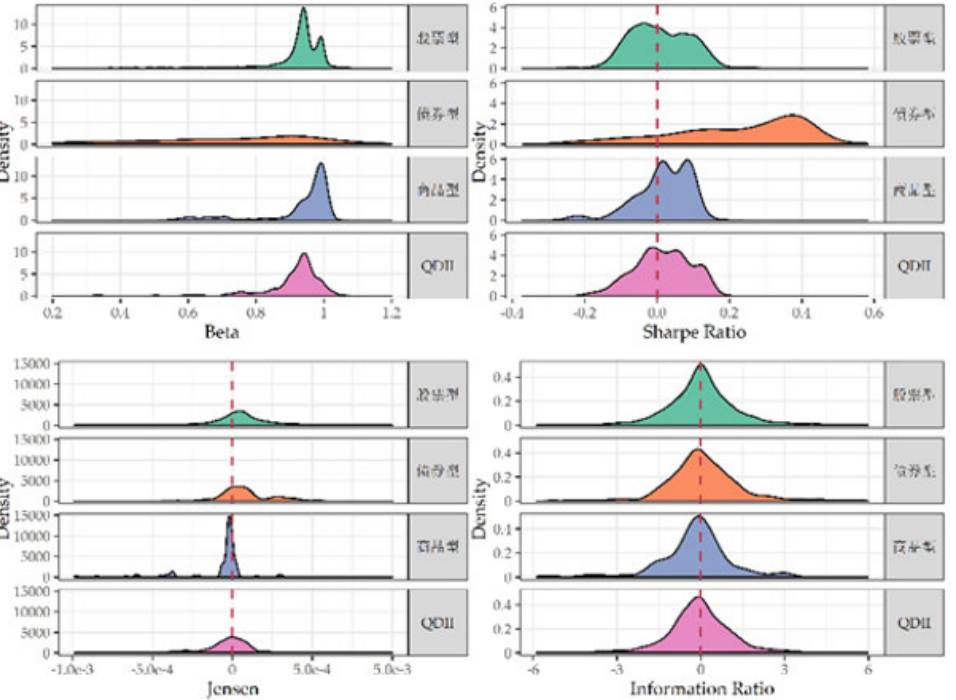

index funds
All Fund Managers

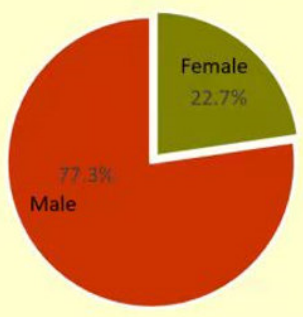

The First Place Fund Managers

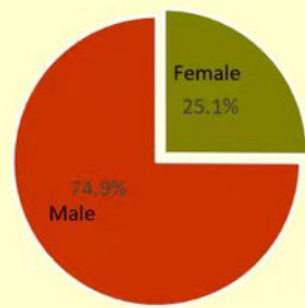

The Second、Thrid Place Fund Managers

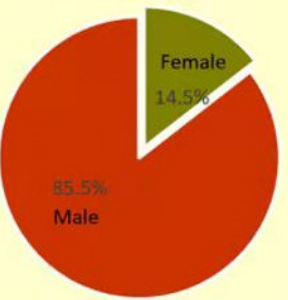

Figure 5. Index funds-gender distribution of fund managers

Index Funds - Educational Qualification Distribution of Fund Managers

All Fund Managers

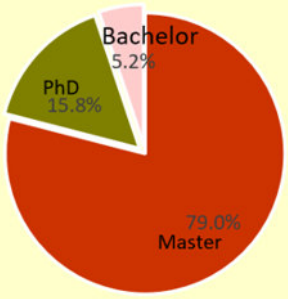

The First Place Fund Managers

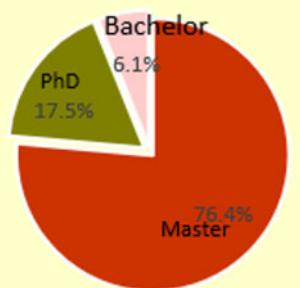

The Second、Thrid Place Fund Managers

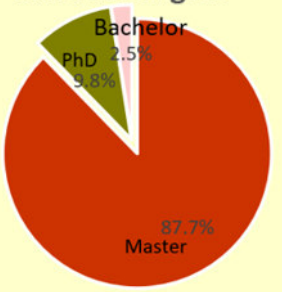

Figure 6. Index Fund-Fund Manager's Educational Qualification Distribution 
Table 1. Performance comparison of CSI 300 index enhanced and passive index funds

\begin{tabular}{|c|c|c|c|}
\hline & (1) & (2) & (3) \\
\hline Variable & Enhanced & Passive & Enhanced vsPassive \\
\hline \multirow{2}{*}{ TE(abs) } & 0.0019 & 0.0008 & $0.0011 * * *$ \\
\hline & $(0.0012)$ & $(0.0004)$ & $(0.0002)$ \\
\hline \multirow{2}{*}{$\mathrm{TE}(\mathrm{sd})$} & 0.0030 & 0.0013 & $0.0017 * * *$ \\
\hline & $(0.0020)$ & $(0.0009)$ & $(0.0003)$ \\
\hline \multirow{2}{*}{ Beta } & 0.8583 & 0.9216 & $-0.0633 * *$ \\
\hline & $(0.1724)$ & $(0.0601)$ & $(0.0281)$ \\
\hline \multirow{2}{*}{ Sharpe Ratio } & 0.1145 & 0.1005 & $0.0141 * * *$ \\
\hline & $(0.0199)$ & $(0.0203)$ & $(0.0041)$ \\
\hline \multirow{2}{*}{ Treynor } & 0.0014 & 0.0012 & $0.0002 * * *$ \\
\hline & $(0.0003)$ & $(0.0003)$ & $(0.0001)$ \\
\hline \multirow{2}{*}{ Jensen } & 0.0002 & 0.0001 & $0.0001 * * *$ \\
\hline & $(0.0002)$ & $(0.0001)$ & $(0.0000)$ \\
\hline \multirow{2}{*}{$\begin{array}{l}\text { Information } \\
\text { Ratio }\end{array}$} & 0.3552 & -0.2793 & 0.6345 \\
\hline & $(3.2874)$ & $(1.3664)$ & $(0.5450)$ \\
\hline Observations & 57 & 41 & 98 \\
\hline
\end{tabular}

Table 2. Performance Comparison of Various Index Funds

\begin{tabular}{|c|c|c|c|c|c|c|}
\hline & $(1)$ & $(2)$ & $(3)$ & $(4)$ & $(5)$ & $(6)$ \\
\hline \multirow{2}{*}{ Variable } & $\begin{array}{c}\text { Mean } \\
\text { (Stock) }\end{array}$ & $\begin{array}{c}\text { Mean } \\
\text { (Bond) }\end{array}$ & $\begin{array}{c}\text { Mean } \\
\text { (Commdity) }\end{array}$ & $\begin{array}{c}\text { Stock vs } \\
\text { Bond }\end{array}$ & $\begin{array}{c}\text { Stock vs } \\
\text { Commdity }\end{array}$ & $\begin{array}{c}\text { Bond vs } \\
\text { Commdity }\end{array}$ \\
\hline \multirow{2}{*}{ TE(abs) } & 0.0017 & 0.0006 & 0.0008 & $0.0011^{* * *}$ & $0.0009 * * *$ & $-0.0002^{* *}$ \\
\cline { 2 - 7 } & $(0.0022)$ & $(0.0007)$ & $(0.0015)$ & $(0.0001)$ & $(0.0002)$ & $(0.0001)$ \\
\hline \multirow{2}{*}{ TE(sd) } & 0.0028 & 0.0010 & 0.0013 & $0.0019 * * *$ & $0.0015 * * *$ & $-0.0004 * *$ \\
\cline { 2 - 7 } & $(0.0037)$ & $(0.0012)$ & $(0.0022)$ & $(0.0002)$ & $(0.0004)$ & $(0.0002)$ \\
\hline \multirow{2}{*}{ Beta } & 0.8996 & 0.6987 & 0.9169 & $0.2009 * * *$ & -0.0173 & $-0.2182^{* * *}$ \\
\cline { 2 - 7 } & $(0.1671)$ & $(0.3952)$ & $(0.1599)$ & $(0.0096)$ & $(0.0171)$ & $(0.0408)$ \\
\hline \multirow{2}{*}{ Sharpe Ratio } & 0.0094 & 0.2275 & 0.0184 & $-0.2181 * * *$ & -0.0090 & $0.2091 * * *$ \\
\cline { 2 - 7 } & $(0.0849)$ & $(0.1869)$ & $(0.0733)$ & $(0.0048)$ & $(0.0087)$ & $(0.0193)$ \\
\hline \multirow{2}{*}{ Treynor } & 0.0034 & 0.0003 & 0.0001 & 0.0030 & 0.0032 & $0.0002^{*}$ \\
\cline { 2 - 7 } & $(0.2252)$ & $(0.0010)$ & $(0.0010)$ & $(0.0105)$ & $(0.0229)$ & $(0.0001)$ \\
\hline \multirow{2}{*}{ Jensen } & 0.0000 & 0.0001 & -0.0001 & $-0.0001 * * *$ & $0.0001 * * *$ & $0.0002^{* * *}$ \\
\cline { 2 - 7 } & $(0.0003)$ & $(0.0002)$ & $(0.0002)$ & $(0.0000)$ & $(0.0000)$ & $(0.0000)$ \\
\hline Information & 0.0690 & 0.3068 & -0.0866 & $-0.2379 * * *$ & 0.1556 & $0.3934 *$ \\
\cline { 2 - 7 } Ratio & $(1.7093)$ & $(2.1324)$ & $(1.6523)$ & $(0.0848)$ & $(0.1751)$ & $(0.2297)$ \\
\hline Observations & 4,904 & 466 & 97 & 5,370 & 5,001 & 563 \\
\hline
\end{tabular}

$p<0.1,{ }^{* *} p<0.05,{ }^{* * *} p<0.01$ 
Table 3. Definitions of Variables

\begin{tabular}{|c|c|c|}
\hline \multicolumn{2}{|l|}{ Symbols of variables } & Names of variables \\
\hline \multirow{7}{*}{$\begin{array}{l}\text { Explianed variables } \\
\text { (indexing investment performance) }\end{array}$} & $T E(a b s)$ & Tracking error (absolute value method) \\
\hline & $T E(s d)$ & Tracking error (standard deviation method) \\
\hline & beta & Beta coefficient \\
\hline & sharpe & Sharpe ratio \\
\hline & treynor & Treynor ratio \\
\hline & jensen & Jensen ratio \\
\hline & inf & Information ratio \\
\hline \multirow{2}{*}{$\begin{array}{c}\text { Exlanatory variables } \\
\text { (fund governance structure) }\end{array}$} & ins & Institutional holding \\
\hline & fund & Holding by fund management company \\
\hline \multirow{5}{*}{$\begin{array}{c}\text { Explanatory variables } \\
\text { (charactristics of fund managers and } \\
\text { fund companies) }\end{array}$} & female & The fund manager is a female \\
\hline & $d o c$ & The fund manager is a PHD \\
\hline & $b a c$ & The fund manger is a bachelor \\
\hline & $\ln ($ numfund $)$ & The number of funds \\
\hline & $\ln ($ numman $)$ & The number of fund managers \\
\hline \multirow{2}{*}{$\begin{array}{c}\text { Explanatory variables } \\
\text { (timing and stock selection ability) }\end{array}$} & mta & Timing ability \\
\hline & $s s a$ & Stock selection ability \\
\hline \multirow{5}{*}{ Control Variables } & nav & Reweighting unit net asset value \\
\hline & $\ln ($ asset $)$ & Volume of funds \\
\hline & $\operatorname{conf}$ & Investor's emotion \\
\hline & depi & Domestic economic policy \\
\hline & iefei & International financial environment \\
\hline
\end{tabular}

Table 4. Descriptive statistics

Panel A: Dependent Variables

\begin{tabular}{|c|c|c|c|c|c|c|}
\hline Varibles & Obs & Mean & SD & Min & Median & Max \\
\hline TE $($ abs $)$ & 2257 & 0.12 & 0.136 & 0.00 & 0.08 & 1.75 \\
\hline TE $($ sd $)$ & 2257 & 0.21 & 0.256 & 0.00 & 0.12 & 2.45 \\
\hline beta & 2257 & 0.91 & 0.137 & 0.01 & 0.94 & 1.39 \\
\hline sharpe & 2257 & 0.03 & 0.094 & -0.26 & 0.02 & 0.54 \\
\hline treynor & 2257 & 0.01 & 0.120 & -0.72 & 0.02 & 1.41 \\
\hline jensen & 2257 & 0.00 & 0.025 & -0.37 & 0.01 & 0.15 \\
\hline inf & 2257 & 0.06 & 1.714 & -22.62 & 0.00 & 35.96 \\
\hline
\end{tabular}

Panel B: Independent Variables

\begin{tabular}{|c|c|c|c|c|c|c|}
\hline Varibles & Obs & Mean & SD & Min & Median & Max \\
\hline ins & 2257 & 0.38 & 0.350 & 0.00 & 0.25 & 1.00 \\
\hline fund & 2257 & 0.03 & 0.128 & 0.00 & 0.00 & 1.00 \\
\hline female & 2257 & 0.28 & 0.447 & 0.00 & 0.00 & 1.00 \\
\hline doc & 2257 & 0.23 & 0.419 & 0.00 & 0.00 & 1.00 \\
\hline bac & 2257 & 0.05 & 0.227 & 0.00 & 0.00 & 1.00 \\
\hline $\ln$ (numfund) & 2257 & 4.84 & 0.587 & 1.61 & 5.03 & 5.39 \\
\hline $\ln ($ numman) & 2257 & 3.60 & 0.477 & 1.10 & 3.81 & 4.11 \\
\hline mta & 2257 & 0.00 & 0.049 & -0.46 & -0.00 & 1.00 \\
\hline ssa & 2257 & 0.02 & 0.091 & -1.00 & 0.02 & 0.78 \\
\hline
\end{tabular}

Panel C: Control Variables

\begin{tabular}{|c|c|c|c|c|c|c|}
\hline Varibles & Obs & Mean & SD & Min & Median & Max \\
\hline nav & 2257 & 1.26 & 2.548 & 0.26 & 1.05 & 118.93 \\
\hline $\ln ($ asset $)$ & 2257 & 19.78 & 1.724 & 15.21 & 19.60 & 24.56 \\
\hline conf & 2257 & 54.63 & 4.094 & 44.77 & 54.13 & 62.24 \\
\hline depi & 2257 & 60.21 & 7.121 & 46.54 & 56.92 & 76.80 \\
\hline iefei & 2257 & 44.82 & 6.685 & 23.02 & 49.60 & 53.74 \\
\hline
\end{tabular}


Table 5. Fund governance structure and investment performance

\begin{tabular}{|c|c|c|c|c|c|c|c|}
\hline & $(1)$ & $(2)$ & $(3)$ & $(4)$ & $(5)$ & $(6)$ & $(7)$ \\
\hline \multirow{3}{*}{ ins } & $T E(a b s)$ & $T E(s d)$ & beta & sharpe & treynor & jensen & inf \\
\cline { 2 - 8 } & $-0.038^{* * *}$ & $-0.052^{* * *}$ & $-0.051^{* * *}$ & $0.032^{* * *}$ & 0.001 & 0.002 & $0.326^{* * *}$ \\
\cline { 2 - 8 } fund & $(-4.47)$ & $(-3.39)$ & $(-4.99)$ & $(5.88)$ & $(0.21)$ & $(1.32)$ & $(2.74)$ \\
\cline { 2 - 8 } & $0.083^{* * *}$ & $0.112^{* *}$ & $-0.065^{* *}$ & $-0.026^{* *}$ & $-0.031^{* *}$ & $-0.010^{* *}$ & 0.071 \\
\hline \multirow{3}{*}{ nav } & $(2.75)$ & $(2.33)$ & $(-1.98)$ & $(-2.19)$ & $(-2.35)$ & $(-2.44)$ & $(0.32)$ \\
\cline { 2 - 8 } & -0.002 & -0.004 & -0.000 & 0.000 & 0.000 & 0.000 & -0.001 \\
\hline \multirow{2}{*}{ In (asset) } & $(-1.56)$ & $(-1.54)$ & $(-0.14)$ & $(0.66)$ & $(0.37)$ & $(0.73)$ & $(-0.26)$ \\
\cline { 2 - 8 } & $-0.004^{* *}$ & $-0.011^{* * *}$ & 0.003 & $0.005^{* * *}$ & $0.003^{* *}$ & -0.000 & 0.029 \\
\hline \multirow{2}{*}{ conf } & $(-2.11)$ & $(-3.44)$ & $(1.42)$ & $(4.98)$ & $(2.37)$ & $(-0.72)$ & $(1.41)$ \\
\cline { 2 - 8 } & $0.006^{* *}$ & $0.017^{* * *}$ & 0.002 & 0.002 & $0.009^{* * *}$ & $-0.001^{*}$ & 0.010 \\
\hline \multirow{2}{*}{ depi } & $(2.42)$ & $(2.95)$ & $(0.88)$ & $(1.30)$ & $(4.01)$ & $(-1.84)$ & $(0.32)$ \\
\cline { 2 - 8 } & -0.000 & -0.002 & $-0.005^{* * *}$ & $0.004^{* * *}$ & $0.003^{* * *}$ & $0.001^{* * *}$ & -0.013 \\
\hline \multirow{2}{*}{ iefei } & $(-0.35)$ & $(-0.87)$ & $(-4.48)$ & $(6.72)$ & $(3.23)$ & $(2.82)$ & $(-0.98)$ \\
\cline { 2 - 8 } & $-0.002^{* * *}$ & $-0.004^{* *}$ & $0.002^{* *}$ & $0.004^{* * *}$ & $0.003^{* * *}$ & -0.000 & -0.002 \\
\hline \multirow{2}{*}{ Constant } & $(-2.76)$ & $(-2.43)$ & $(2.38)$ & $(8.00)$ & $(4.82)$ & $(-0.65)$ & $(-0.17)$ \\
\cline { 2 - 8 } & -0.022 & -0.166 & $0.995^{* * *}$ & $-0.568^{* * *}$ & $-0.854^{* * *}$ & $0.025^{* *}$ & -0.287 \\
\hline \multirow{2}{*}{$N$} & $(-0.33)$ & $(-1.21)$ & $(16.16)$ & $(-15.98)$ & $(-15.83)$ & $(2.06)$ & $(-0.37)$ \\
\hline
\end{tabular}

$\mathrm{t}$ statistics in parentheses

$* \mathrm{p}<0.1, * * \mathrm{p}<0.05, * * * \mathrm{p}<0.01$

Table 6. Characteristics and investment performance of fund managers and fund companies

(1) (2) (3) (4) (5) (6) (7)

\begin{tabular}{|c|c|c|c|c|c|c|c|}
\hline & $T E(a b s)$ & $T E(s d)$ & beta & sharpe & treymor & jensen & inf \\
\hline \multirow{2}{*}{ female } & -0.005 & -0.003 & $-0.014^{* *}$ & 0.005 & -0.002 & 0.001 & 0.005 \\
\hline & $(-0.67)$ & $(-0.21)$ & $(-1.99)$ & (1.31) & $(-0.42)$ & $(0.48)$ & $(0.06)$ \\
\hline \multirow{2}{*}{$d o c$} & $0.024^{* * *}$ & $0.036^{* *}$ & $-0.017^{* *}$ & -0.003 & -0.005 & $-0.004^{* * *}$ & -0.124 \\
\hline & $(2.96)$ & $(2.51)$ & $(-2.25)$ & $(-0.81)$ & $(-0.87)$ & $(-2.73)$ & $(-1.50)$ \\
\hline \multirow{2}{*}{ bac } & $-0.017^{*}$ & -0.020 & $0.019^{* *}$ & $-0.008^{*}$ & 0.001 & 0.003 & -0.041 \\
\hline & $(-1.83)$ & $(-0.88)$ & $(2.12)$ & $(-1.67)$ & $(0.16)$ & $(1.32)$ & $(-0.32)$ \\
\hline \multirow{2}{*}{$\ln$ (numfund) } & -0.017 & 0.010 & -0.017 & -0.003 & -0.001 & 0.003 & -0.062 \\
\hline & $(-1.16)$ & $(0.36)$ & $(-1.20)$ & $(-0.46)$ & $(-0.11)$ & (1.8) & $(-0.32)$ \\
\hline \multirow{2}{*}{$\ln ($ numman $)$} & -0.010 & -0.055 & $0.046^{* *}$ & 0.002 & 0.001 & -0.006 & 0.071 \\
\hline & $(-0.46)$ & $(-1.47)$ & $(2.38)$ & $(0.27)$ & $(0.12)$ & $(-1.61)$ & $(0.27)$ \\
\hline \multirow{2}{*}{ nav } & $-0.002^{*}$ & $-0.004^{*}$ & -0.000 & 0.000 & 0.000 & 0.000 & -0.001 \\
\hline & $(-1.68)$ & $(-1.67)$ & $(-0.12)$ & $(0.79)$ & $(0.38)$ & $(0.60)$ & $(-0.14)$ \\
\hline \multirow{2}{*}{$\ln$ (asset) } & $-0.006^{* * *}$ & $-0.014^{* * *}$ & 0.001 & $0.007^{* * *}$ & $0.004^{* * *}$ & 0.000 & $0.041^{* *}$ \\
\hline & $(-3.37)$ & $(-4.47)$ & $(0.57)$ & $(6.50)$ & (2.93) & $(0.75)$ & $(2.03)$ \\
\hline \multirow{2}{*}{$\operatorname{conf}$} & $0.005^{*}$ & $0.015^{* *}$ & 0.004 & 0.001 & $0.009^{* * *}$ & -0.001 & 0.008 \\
\hline & $(1.70)$ & $(2.54)$ & $(1.56)$ & $(0.90)$ & (3.91) & $(-1.43)$ & $(0.26)$ \\
\hline \multirow{2}{*}{ depi } & 0.000 & -0.001 & $-0.006^{* * *}$ & $0.004^{* * *}$ & $0.003^{* * *}$ & $0.000^{* *}$ & -0.013 \\
\hline & $(0.17)$ & $(-0.59)$ & $(-4.79)$ & $(6.83)$ & $(3.06)$ & $(2.42)$ & $(-0.94)$ \\
\hline \multirow{2}{*}{ iefei } & $-0.002^{* *}$ & $-0.003^{* *}$ & $0.001^{*}$ & $0.004^{* * *}$ & $0.003^{* * *}$ & -0.000 & -0.001 \\
\hline & $(-2.01)$ & $(-2.02)$ & (1.69) & $(8.09)$ & $(4.68)$ & $(-0.85)$ & $(-0.11)$ \\
\hline \multirow{2}{*}{ Constant } & $0.154^{* *}$ & 0.054 & $0.893^{* * *}$ & $-0.579^{* * *}$ & $-0.874^{* * *}$ & 0.018 & -0.300 \\
\hline & $(2.06)$ & $(0.38)$ & $(13.29)$ & $(-16.16)$ & $(-15.16)$ & (1.43) & $(-0.37)$ \\
\hline$N$ & 2257 & 2257 & 2257 & 2257 & 2257 & 2257 & 2257 \\
\hline
\end{tabular}

$\mathrm{t}$ statistics in parentheses

$* \mathrm{p}<0.1, * * \mathrm{p}<0.05, * * * \mathrm{p}<0.01$ 
Table 7. Stock selection ability, timing ability and investment performance

(1) (2) (3) (4) (5) (6) (7)

\begin{tabular}{|c|c|c|c|c|c|c|c|}
\hline & $T E(a b s)$ & $T E(s d)$ & beta & sharpe & treynor & jensen & $\inf$ \\
\hline \multirow{2}{*}{$m t a$} & $-0.144 * *$ & $-0.273 * *$ & $-0.764 * * *$ & $0.241 * * *$ & $-0.126 * * *$ & $0.022 * *$ & 1.213 \\
\hline & $(-2.44)$ & $(-2.48)$ & $(-13.49)$ & $(7.57)$ & $(-3.16)$ & $(2.15)$ & $(1.62)$ \\
\hline \multirow{2}{*}{ ssa } & $0.055^{*}$ & $0.123 * *$ & $0.063^{* *}$ & $0.076 * * *$ & $0.144^{* * * *}$ & $0.081 * * *$ & 0.272 \\
\hline & (1.77) & (2.11) & $(2.09)$ & (4.49) & $(6.82)$ & (14.84) & $(0.68)$ \\
\hline \multirow{2}{*}{ nav } & -0.002 & $-0.004^{*}$ & -0.000 & 0.000 & 0.000 & 0.000 & -0.001 \\
\hline & $(-1.38)$ & $(-1.83)$ & $(-0.06)$ & $(0.55)$ & $(0.64)$ & $(0.70)$ & $(-0.05)$ \\
\hline \multirow{2}{*}{$\ln$ (asset) } & $-0.007^{* * *}$ & $-0.015^{* * *}$ & $0.004^{* * *}$ & $0.006^{* * *}$ & $0.004^{* * *}$ & -0.000 & $0.037^{*}$ \\
\hline & $(-4.10)$ & $(-4.79)$ & (2.64) & (6.91) & (3.62) & $(-0.03)$ & $(1.72)$ \\
\hline \multirow{2}{*}{$\operatorname{conf}$} & $0.007^{* *}$ & $0.018^{* * *}$ & 0.002 & 0.002 & $0.010^{* * *}$ & -0.000 & 0.007 \\
\hline & $(2.37)$ & (3.17) & $(0.78)$ & (1.13) & $(4.71)$ & $(-0.83)$ & $(0.20)$ \\
\hline \multirow{2}{*}{ depi } & -0.001 & -0.003 & $-0.005^{* * *}$ & $0.003^{* * *}$ & $0.003^{* * *}$ & 0.000 & -0.013 \\
\hline & $(-0.56)$ & $(-1.06)$ & $(-3.69)$ & $(4.80)$ & $(2.95)$ & $(1.30)$ & $(-0.79)$ \\
\hline \multirow{2}{*}{ iefei } & $-0.002^{* *}$ & $-0.004^{* *}$ & $0.002^{*}$ & $0.004^{* * *}$ & $0.003^{* * *}$ & -0.000 & -0.002 \\
\hline & $(-2.41)$ & $(-2.30)$ & (1.79) & (7.23) & (4.74) & $(-1.10)$ & $(-0.13)$ \\
\hline \multirow{2}{*}{ Constant } & 0.012 & -0.127 & $0.913^{* * *}$ & $-0.573^{* * *}$ & $-0.887^{* * *}$ & 0.016 & -0.215 \\
\hline & $(0.16)$ & $(-0.94)$ & (13.17) & $(-14.72)$ & $(-18.23)$ & $(1.25)$ & $(-0.24)$ \\
\hline$N$ & 2257 & 2257 & 2257 & 2257 & 2257 & 2257 & 2257 \\
\hline
\end{tabular}

t statistics in parentheses

$* \mathrm{p}<0.1, * * \mathrm{p}<0.05, * * * \mathrm{p}<0.01$ 